\title{
AUDITING:
}

A Journal of Practice

\& Theory

Vol. 21, No. 1

March 2002

\section{Feasibility and Economics of Continuous Assurance}

\section{Michael G. Alles, Alexander Kogan, and Miklos A. Vasarhelyi}

\begin{abstract}
SUMMARY
Given the growing interest in the topic, both in practice and academia, it is timely and important to examine the concept of continuous assurance (CA) and the possible paths along which such services will evolve. There has been a tendency to see CA purely from the point of view of its technological enablers. As such, it has virtually been taken for granted that $\mathrm{CA}$ will follow as a matter of course. What has been less thought through is the business architecture that must underlie CA. In particular, we show that the key driver of CA is the demand for it. While there may be many economic transactions between the company and its stakeholders that could benefit from the provision of $\mathrm{CA}$, there is no guarantee that CA is either cost effective-the only way of enhancing efficiency - or actually has to be continuous. Other factors that will affect the development of CA are the need for a new infrastructure to pay for it, as well as concerns about the independence of the assurors. We also identify some important research issues.
\end{abstract}

Keywords: continuous assurance; continuous auditing; audit demand; payment infrastructure; auditor independence.

\section{INTRODUCTION}

$\mathrm{W}$ ith the acceleration of information flows and the availability of online real-time enterprise systems, the accounting profession has started to reconsider what an audit means and how it is carried out. It is now widely believed that the "archival audit" where the auditor comes in at the end of the year, examines statements, and issues ex post opinions will inevitably be supplemented, if not replaced, by a more timely, close-to-the-event semi-supervisory function, where independent assurors will work with both third-party stakeholders and firms to provide new forms of

assurance products (Kinney 1999; Elliot 1997; Vasarhelyi forthcoming). In particular, there has Q5 been growing interest in the timeliness of assurance services. As Elliot $(1997,64)$ states, "On-line reporting based on databases updated in real time will be less wedded to current protocols for periodicity, creating a parallel evolution toward continuous auditing. Continuous auditing may lea to continuous reporting that supplements and eventually replaces the annual audit report. To audit effectively in these environments, auditors will use electronic sensors, software agents and computerized audit programming models.' Subsequently, the scope of such services has been expanded by the AICPA from auditing to assurance. Elliott $(2002,7)$ recently has forcefully argued, "The advantages of electronic business reporting will provide a market for - indeed, the necessity of - continuous assurance."

Michael G. Alles is an Associate Professor, and Alexander Kogan and Miklos A. Vasarhelyi are Professors, all at Rutgers University.

We thank Roger Debreceny, two anonymous referees, and the editor for many helpful comments. 
Given this context, it is timely and important to examine the concept of continuous assurance (CA) and the possible paths along which such services will evolve. There has been a tendency to see CA purely from the point of view of its technological enablers. As such technology as Enterprise Resource Planning (ERP) systems, broadband networking, and bar coding becomes ubiquitous, it has been virtually taken for granted that CA will follow in its wake as a matter of course. What has been less thought through is the business architecture that must underlie continuous assurance. In this paper we complement the technological focus of the literature by examining the economic factors that will determine the evolution of CA.

In the next section we examine the components of assurance. Our analysis indicates that demand is the key driver of continuous assurance, which we examine further in section three. The business architecture of CA is discussed in the fourth section. Assuror's independence, along with the related issue of the technical architecture of CA, is also an essential aspect of a feasible continuous assurance environment, and is examined in the fifth section. Section six suggests issues for further research, while the last section provides concluding remarks.

\title{
Components of Assurance
}

\section{ESSENTIAL COMPONENTS OF ASSURANCE}

The first step in understanding continuous assurance is to clarify what is meant by the first part of that term: what exactly is "continuous"? More generally, how will CA differ from the myriad forms of assurance and auditing that currently exist? Also, does a distinction need to be drawn between continuous assurance and continuous auditing, when those terms are frequently used interchangeably? Given the evolving state of these concepts, it is not surprising that there is a lack of clarity on these matters. It is equally obvious, however, that an analysis of CA cannot proceed without first reaching a consensus on what distinguishes it from auditing as it is practiced today.

The AICPA's Special Committee on Assurance Services (SCAS - more popularly known as the "Elliot Committee") defines assurance services as "independent professional services that improve the quality of information, or its context, for decision makers." It then further describes the scope of assurance services in the following way:

\begin{abstract}
Assurance services might involve any type of information. Information can be financial or nonfinancial. It can be about discrete phenomena or about processes or systems (such as internal control or decision models). It can be direct (such as information about a product) or indirect (such as information about someone else's assertion about a product). It can be internal or external to the decision maker. The goal of assurance services is information improvement, not the issuance of a report on it (though there might be a report).
\end{abstract}

Clearly the annual financial statement audit is only one special case of an assurance service. Thus, in this paper we shall use the term "auditing" to refer specifically to the legally mandated financial statement audit and the term "assurance" for the broader set of products that meet the AICPA's definition. Examples of such assurance services include SysTrust (AICPA 1997), WebTrust (AICPA 1998; Srivastava and Mock 1999-2000; Greenstein 1998) and ElderTrust Plus. Given this distinction, we shall also use the terms "assuror" and "assuree" as the equivalent in the broader assurance setting of the terms "auditor" and "auditee" in the financial statements context. However it needs to be kept in mind that often the terms "continuous auditing" and "continuous assurance" are used interchangeably, even though, as we shall argue, there are fundamental differences between them. Further confusion is created by the use of such terms as "real-time auditing" and "online auditing."

1 http://www.aicpa.org/assurance/about/comstud/defncom.htm. See also Elliot (1997). 
The current status of the field of continuous assurance is such that few pure continuous assurance applications can be found (as examples, see Vasarhelyi and Halper 1991; Voarino and Vasarhelyi 2001; Wechler 2001), although many firms are evolving toward very careful monitoring of missioncritical applications and corporate information systems are being progressively integrated, so that the basics for a monitoring and assurance architecture are falling into place.

We first examine the common aspects of all assurance service. There are three essential components in the process of providing assurance:

- Capturing by the assuree of information related to the transactions, processes, and environment that are the subjects of assurance.

- Monitoring and analyzing by the assuror the transactions, processes, and records to ensure the reliability of the information.

- Communicating the outcome of the assurance engagement by the assuror.

When the assurance process is decomposed into these three components, it becomes evident why it is necessary to specify exactly what is continuous in CA. Let us consider first the methodology for recording business transactions.

\section{Continuous Recording of Business Transactions}

With the ubiquity of bar coding, scanning, automatic transaction recording, and the low cost of data storage and retrieval, companies no longer need be constrained to rely on conventional doubleentry bookkeeping and a chart of accounts to aggregate and record information. Smart warehouses utilizing radio frequency smart-chip-based labels, as well as Internet-based implementations of electronic data interchange (EDI) and newer business-to-business protocols such as ebXML and BizTalk, enable low-cost business-information capture at the source. Developments such as Supply Chain Management (SCM), Business Process Reengineering, Activity-Based Management, and the Balanced Scorecard give a strategic impetus to the development of real-time information gathering and decision support systems (Vasarhelyi and Greenstein 2001).

As a result, all but the smallest firms have or soon will have the capability to record such transactions in real time. While transactions take place in discrete time, if there are enough of them, we can use the colloquial descriptor "continuous." Hence, in most high-volume organizations, transactions can be said to both to take place and, potentially, be recorded virtually "continuously." Thus, to a large extent, the first step in the assurance process - information capture - is already nearly continuous. Note, however, that the assuree is carrying out real-time information capture for its own business sake, rather than to fulfill the needs of a third-party assuror.

However, while the first component of assurance can at least in theory be made nearly continuous with relative ease, the second component of assurance - monitoring and analysis by the assuror-presents a major challenge. Just because the underlying data is being gathered continuously, does that mean that assurance itself can or should also be carried out in the same way? What precisely does it mean to assure "continuously"? We will address these issues in subsequent sections.

\section{Transaction Monitoring, Assurance, and Reporting}

In the extreme, there are two diametrically opposed approaches to carrying out continuous assurance: continuous monitoring of the assuree's system, and continuous reprocessing of all the assuree's information using a mirror system. If the assuror's system were mirroring the company's ERP system, then it would record transactions at the same time as the company. The company's data would then be monitored and analyzed on a continuous basis, in contrast to current practices where an auditor conducting the annual financial statements audit examines the company's transactions only periodically or on a case-by-case basis. While the mirroring approach can indeed be used for 
providing limited scope CA (such as individual account balance), for assurance on a wider scope, continuous system monitoring appears to be easier to implement. ${ }^{2}$

Regardless of which approach is adopted, much of the increasing practitioner interest in CA stems from the belief that the way in which the mandated annual audit takes place will have to change to reflect and to take advantage of the new real-time enterprise systems that companies are installing. Thus auditors, as a way of reducing the cost and increasing the effectiveness of the annual financial statements audit, will increasingly install monitoring software that will overlay the company's own IT systems, upon which these systems can then be "piggybacked" to offer broader assurance products.

As for the first two components of the assurance process, the third component-reporting on the outcome of the assurance engagement - can also be done virtually continuously using existing and emerging information technologies, in this case, those based on the nearly ubiquitous Internet connectivity. The Web, email, and peer-to-peer computing are among the most likely technologies to underlie the distribution of assurance reports. However, this is only a statement of technological possibilities, and whether continuous reporting of assurance services will ever be realized is not a function of technology, but of whether parties actually wish to have reporting in real time, and assuming that there does not exist organizational or legal barriers to continuous assurance reports.

The fundamental point is that assurance is not undertaken for its own sake, but because it facilitates some other processes involving the assuree and third parties. For assurance to exist, the fact that the underlying transactions and processes have been assured (that the first two components of the assurance process have been undertaken) must be communicated to the interested parties. In the absence of a legal mandate to offer assurance, such a report will only be issued if some party demands it, and another party (not necessarily the same one) is willing to pay for it.

Now we can see the key distinction between continuous assurance and the concept of continuous auditing that has been discussed (Vasarhelyi and Halper 1991; Vasarhelyi et. al 1991; Rezaee et al 2002). The latter is best described as the application of modern information technologies to the standard audit products, be they the mandated annual audit opinion or internal auditing for control. Continuous auditing is another step in the path of the evolution of the financial audit from manual to systems-based methods. The literature on continuous auditing can restrict itself to technical matters, working under the assumptions that the demand for the mandated audit is a given and that the emerging technologies will be adopted because they are cheaper and more effective than current audit methods. By contrast, continuous assurance sees continuous auditing as only a subset of a much wider range of new, nonstatutory products and services that will be made possible by these technologies. Hence, it is our opinion that the rationale for continuous assurance cannot be taken for granted in the same way that it can for continuous auditing.

In other words, the most important driver of CA is the demand for it and the means by which the assuror will be reimbursed for providing it. The next section examines whether demand is a necessary and sufficient condition, or just a prerequisite for the development of a full-fledged CA environment.

\section{Inherent Demand for Assurance}

\section{DEMAND FOR CONTINUOUS ASSURANCE}

One argument concerning demand is that assurance is value adding in any transaction. The Elliot committee is of the opinion that there will be a need for assurance in any generic exchange of

\footnotetext{
2 Such system monitoring would have to include continuous testing of internal controls, continuous monitoring of transaction flow integrity, and continuous monitoring of the system's digital signatures to assure that the system has no unauthorized changes. Applications have their natural timing, and analytical procedures for their monitoring must be performed along this cycle. For example, many organizations bill in daily cycles throughout the month. Consequently, billing completion tests can only be performed for one daily cycle at a time. Note that selective continuous reprocessing of some information may still be desirable.
} 
goods or services. Such a view is reinforced by the modern stakeholder view of the firm, where it is seen as a nexus of a far wider set of relationships than that between the firm's managers and its current and potential owners, which is the basis of the mandated audit:

The audit tradition is a professional asset of incalculable value. It derives from the marketplace need for high-quality, decision-making information. The financial statement audit provides assurance that an information set presented to investors and creditors is reliable. But the marketplace need for high-quality information is far greater than the need for reliable historical-cost-basis financial statements. Thus, assurance services not only respond to the growth problems of the audit industry, they also adjust the audit tradition to the wider marketplace....The CPA's customer base can (and should) be all users of decision-making information. (Elliott, 1997, 61)

Companies also make a very large number of selective disclosures in the ordinary course of business. These include periodic reporting to banks on debt covenants, tax disclosure for federal, state, local, and other authorities, OSHA, FTC, FCC, and other regulatory mandated disclosures and specific disclosures for obtaining credit. The emerging practice of global SCM increases the upstream and downstream set of players who have a stake in the firm's actions, some of who, because they do not have direct interactions with the firm, have never been considered as stakeholders before.

The Elliot Committee envisages that the progressive availability of CA technologies and their visibility through well-publicized examples will precipitate changes in the contractual terms between these stakeholders and the company, to include provisions for some form of high-level monitoring and exception reporting. The existence of transactions between stakeholders is not sufficient, though, for there also to be an accompanying demand for assurance. Despite the AICPA's contention that assurance is beneficial whenever decisions are made, it is not necessarily the case that assurance provides enough of a payback to justify its cost.

\section{Is Demand for Assurance Guaranteed?}

Many of the transactions described above are a routine part of business, so if there is a demand for assurance, how is it being met now? Clearly some of these transactions already have assurance attached to them, most notably, in the areas of loan applications and compliance with debt covenants (Woodroof and Searcy 2001). It is also clear, though, that many of the transactions cited have no current assurance attached. For example, business partners, employees, and local communities of some privately held companies may be quite interested in the firm's audited financial statements, and may even be willing to pay for such statements. Nevertheless, most private companies do not seem to be interested in making them available.

Although accounting research has identified the benefits of broader disclosure, such as the reduction in the cost of capital (Botosan 1997), additional higher frequency public reporting does have serious problems. These problems are not limited to the inevitable additional costs of reporting, which may be trivial in certain cases, but include such serious managerial issues as possible legal liability and competitive disadvantages due to increased disclosure. It is also understandable that managers are not eager to disclose more than required, since it will reduce their information asymmetry advantages, and decrease managerial discretion. Additionally, voluntary disclosure, once started, can be very difficult to stop since such termination will likely be considered a negative signal. ${ }^{3}$

3 A recent SEC ruling that may have a major impact on information flows concerning a publicly traded company is the socalled "Fair Disclosure" (FD) regulation, which requires that there be no selective disclosure of value relevant information. If this regulation were interpreted as originally envisaged, it would suggest that the only form of reporting, and hence, of assurance, is that based on public reporting - which would necessarily imply that reimbursement would be, as is the case now, made by the assuree. However, the SEC has recently amended the interpretation of regulation FD to allow firms to continue to make selective disclosures to noninvesting stakeholders. See http://www.sec.gov/rules/final/337881.htm 
It is notable that although the Jenkins Committee recommended a separate filing of the fourth quarter 10-Qs, this recommendation has not been implemented (although the information in the fourth quarter 10-Qs can be derived from the annual report and from the first three 10-Q filings). While most companies conduct monthly closings, there is no evidence of monthly financial statements being made publicly available (however, earnings warnings have become very common). Moreover, anecdotal evidence seems to suggest that although the audit teams can gain access to the monthly statements, they do not use them in conducting their annual audit, despite the known research findings that the accuracy of analytical procedures improves if applied to higher frequency data.

Even in the case of publicly available financial statements, such as quarterly $10-\mathrm{Q}$ filings with the SEC, there seems to be no evidence of any market demand for the audit of this information. This may be due to the fact that even sophisticated users may have the mistaken belief about what kind of assurance is actually being provided. In a survey by a large public accounting firm, it was found that 50 percent of financial analysts and money managers believed, wrongly, that the 10-Q reports are audited, while in fact these reports are only reviewed. ${ }^{4}$

Another reason for such an assurance "expectations gap" is that there may already exist alternatives to using assurance as a way of reducing the transaction costs associated with exchange. Trust built through previous experience, the threat of litigation, warranties, reputation, or self-interest may well obviate the need for assurance. Moving away from the arena of financial reporting, an example of self-interest obviating the need for assurance is the case of SCM. In this setting, accuracy in information flows across suppliers and buyers in the value chain is a necessity for such flows to be useful in the first place, and therefore further assurance is redundant. If a company were not willing to be truthful in its disclosures, then it would simply decline to join in this long-term relationship.

An obvious explanation for the current lack of nonmandated assurance is that its greatest use will involve transactions that have not been widely used before. Consider the recent interest in outsourcing critical software needs of a company to an application service provider (ASP). The availability of continuous assurance on the ASP's system may be essential in making such a decision, for while outsourcing of business processes has existed before (e.g., the use of service bureaus), information-age companies face a special vulnerability when outsourcing IT. The client surely has a keen interest in being assured that the ASP is a going concern and that the information systems of the ASP work as promised. Information technology has added a layer of complexity that also precipitates needs for assurance, which hasprom pted the AICPA to introdce itsW ebThust andSysThust assurance services. Future products that the AICPA are investigating include ElderTrust and the provision of assurance relating to health care, e-commerce, and risk management (Salterio 2000). The future prospects of XBRL-based reporting precipitate an entirely new set of needs for assurance at the account level, while the emerging standards like ebXML or BizTalk may provide the setting for transaction-level assurance. ${ }^{6}$ Consider also developments that are only now moving beyond the implementation phase, such as ERP systems, which will undoubtedly generate demand for new types of assurance in the near future.

Q8 4 Private communication with the authors.

5 "WebTrust is an attest-level engagement provided by specially licensed public accounting firms. During the engagement, the WebTrust practitioner 'audits' the online business to verify compliance with Principles and Criteria. The Principles and Criteria address matters such as privacy, security, availability, confidentiality, consumer redress for complaints, and business practices." http://www.aicpa.org/assurance/webtrust/what.htm

"In a SysTrust engagement the CPA evaluates a system against the SysTrust Principles and Criteria and determines whether controls over the system exist. The CPA then performs tests to determine whether those controls were operating effectively during a specified period....The SysTrust report addresses whether management has maintained effective controls over its system. In addition to the attestation report, a SysTrust engagement will include a description of the system examined and in many cases management's assertion about the effectiveness of its controls over the system that enable it to meet the SysTrust criteria." http://www.aicpa.org/assurance/systrust/what.htm

6 See http://www.xbrl.org, http://www.ebxml.org, and http://www.biztalk.org. Note that none of these standards currently provides any kind of assurance tags. It is conceivable that future versions of XBRL may include, for example, means of specifying that the inventory value or the cash amount have been examined and are not materially misstated. The development of the business case and the architecture for such selective CA are important CA research issues for the near future. 
There clearly is a presumption among proponents of a new assurance environment that a significant amount of unmet demand currently exists for these and other transactions, as the Elliot Committee forcefully argues. To take the next step toward CA from this starting point, however, a further assumption has to be made that the reason that assurance is not provided now is that its cost is too high - presumably because of the very absence of the kind of embedded real-time information systems that will underlie CA-rather than because there is no economic need for it. Whether these assumptions are descriptively valid is an empirical issue. To some extent, demand may be latent; that is, in the absence of the possibility of real-time assurance, users have yet to determine how valuable it will be.

\section{Demand for Real-Time Assurance}

Even assuming that demand for assurance will emerge, either for existing transactions or because of innovations in business, in what sense will it be continuous? For example, even if real-time assurance can be provided, will there really be a need for assuring information outside the company with such frequency?

To take the most important subject of assurance today — financial statements - will users such as analysts and potential investors want real-time statements? Can anyone outside the company absorb the quantity of information that real-time systems can provide, and even if they could, would it make sense for them to essentially "second guess" the decisions of managers on a daily basis when they lack the context within which firm managers make decisions? Is the role of accounting as an aggregator and distiller of transactions into meaningful financial statements compromised by continuous reporting? Such frequent reporting will either require a shift in emphasis from income to cash flows, or the automation and real-time execution of allocations, adjustments, and allowances. ${ }^{7}$

In an environment with Balanced Scorecards and SCM, there is an increasing need for company managers to have access to real-time data. Whether those outside the company perceive a similar need is less obvious, for presumably the timing of reporting (and assurance of those reports) must match the time frame of the external parties' decision-making processes. It may be that, except in the case of the largest and most frequently traded companies, analysts and investors make periodic portfolio reviews rather than real-time decisions. The validity of this statement should be studied empirically.

It seems more likely that what users will find valuable is assurance and reporting on demand ( $\mathrm{ad}$ hoc or planned), as they contemplate some transaction, be it an investment, a supply contract, or a job offer. This may be the true source of value for real-time transaction recording and continuous monitoring capabilities - it makes possible the cost-effective and timely production of specialized reports as needed. In the absence of the technology of CA, providing assurance for a nonmandated transaction has to be handled as a special case project, which makes it prohibitively expensive. But with the company's transactions being routinely monitored in real time, much of the work needed to do the assurance has already taken place and can be completed using automated templates and with minimal manual intervention.

In summary, the CA environment that is emerging can be characterized by on-demand reporting for a wide variety of transactions for which there are no alternate means of reducing the transactions costs of exchange other than assurance. However, the presence of demand alone does not guarantee that CA will be viable, as the apparent presence of current unmet demand for assurance demonstrates. Viability is a function not only of supply and demand, but also of the architecture for the compensation of the assuror.

7 On the other hand, continuous assurance need not be over a complete set of financial statements. It may be over a subset of data that is considered to be a good predictor of wider performance (days inventory, days sales, purchase commitments, sales backlog, web site hits). Also, the very ubiquity of the data that real-time systems provide might create information overload, and increase the demand for specialized and tailored reports with assurance attached. 


\section{PAYING FOR CONTINUOUS ASSURANCE \\ Need for a Payment Infrastructure for Assurance}

The way in which assurors will be reimbursed for providing CA products is a function of demand and how that demand is met. Thus, assurance-on-demand for special-case transactions with few parties on either side, such as debt covenants, is the easiest to arrange. As long as the benefits in terms of lower transaction costs exceed the cost of obtaining the assurance, either party may be willing to pay for the assurance. However, when multiple parties are involved on the demand side, it is harder to arrange a mechanism to compensate the assuror. The transaction cost of collecting payment from multiple users makes it inevitable that the assuree will be the only one in a position to arrange for the involvement of the assuror.

This has implications for whether some of the sources of demand will translate into new assurance products. For example, prospective workers may well be interested in an independent assurance regarding the viability and trustworthiness of a company, but it is hard to imagine that, individually, they could afford to arrange for such assurance to be obtained, even in a full CA environment. It is more likely in this case that the company will want to offer a blanket assurance product as a way of enhancing its general recruitment strategy. In some instances, however, such nonspecific assurance may not serve the purpose.

Another problem is that of "free riding." In some cases, the fact that assurance has been undertaken may be as informative as knowing the results of the assurance, which can be inferred from the actions of the firm or of other demand-side clients, even if the report itself remains confidential. Thus in the case of debt covenants, knowing that one bank has not called back their loan after seeing an assured set of financial statements tells other banks all they need to know about the health of the assuree. They can then avoid the cost of paying for the assured report themselves. Again, this will lead to the assurance setting unraveling, unless the assuree is willing to pay for the product itself, as in the mandated audit or as is happening now with SysTrust and WebTrust. While having the assuree pay is a viable option, it does restrict the possible set of CA products to those that the company is willing to pay for, and excludes some of the other types of demand discussed earlier.

\section{Costs of Providing Assurance}

Another pertinent question is who will provide continuous assurance. It is highly unlikely that more than one assuror will provide the CA product as it is inconceivable that the assuree will tolerate the intrusion of having yet another firm install real-time monitoring of its transactions. The anticipated high start-up cost of CA makes it even more unlikely that multiple assurors will provide CA for a company. There exists an argument that the ever-decreasing cost of technology will eventually make the cost of CA insignificant. We take issue with this contention. While the cost of hardware is certainly decreasing, the cost of software is not. Moreover, the major expense associated with complex IT projects such as ERP implementations is not the cost of technology, but of labor in the form of consulting fees and employee training. The main reason why labor costs are high is the complexity of business processes, which makes it very expensive to develop and implement specialized software or even to customize and configure packaged software to adequately support a modern enterprise.

Providing reasonable assurance on the processes, systems, and transactions of complex enterprises is nontrivial and so the start-up cost of any large scope CA project is likely to be high. Since the large fixed cost of installing a real-time CA system is mostly sunk, it becomes crucially important whether the assuror or the assuree absorbs this cost. If it is the former, then will it result in the assuree having the edge in future contract negotiations? Moreover, will the assuror compromise his independence in such an environment, especially if he is already leveraging his insight into the company's transactions by offering management advisory services (MAS)? If the assuree absorbs the start-up cost, and the technology is customized for a specific assuror, then the assuror's independence and 
bargaining power will be enhanced, since replacing him will become too costly. In this case, however, the assuree will be able to lay claim to the CA infrastructure installed on its premises. If and when CA becomes a reality, then the ownership of the CA infrastructure will likely become a contentious issue, and market conditions will likely determine who will absorb the CA start-up costs.

Assurors also cannot ignore the ever-present threat of litigation. As CA moves beyond the mandated audit and addresses issues other than adherence to GAAP, profound questions will arise as to the legal position of the assuror. Given the litigation climate in the U.S., most well-established independent audit providers may not find it cost effective to enter into broad nonstatutory assurance engagements with general distribution of results to third parties. This also makes it more likely that CA will consist of certifications of statements of a more limited nature, with few parties on the demand side. In these cases, the parties getting assurance are clearly specified, and the engagements can be covered by contract law, as opposed to tort law covering the annual audit of financial statements (Elliot 2002). The contract can be used to limit the liability of assurance providers and should therefore facilitate such engagements.

\section{Ownership of Assurance Products}

Another factor that will affect the evolution of $\mathrm{CA}$ is the recognition that continuous assurance reports, regardless of who demands and pays for them, are all ultimately based on the output of the company's real-time transaction systems. While the assuror brings to the table the knowledge, reputation, and tools to make assurance possible, assurance itself is essentially an overlay on the company's proprietary information. Thus, even while the assuror adds value by improving the quality of this information, the company may be able to retain some "reach through" rights on any transformations of its information into new assurance products and services. In other words, the assuree, not the assuror, may determine how the output of the assurance process is used.

There is an implication in some of the literature on CA that the assuror will be in a position to produce and sell all manner of innovative CA products, including comparisons between firms. However, that view has to be tempered because the assuree will be in a position to determine which CA products (if any) a third-party assuror will be allowed to provide to the wider market, let alone derive revenue from. Of course, the assuree may not be able to interfere with the provision of nonfirm-specific products and services resulting from the assurance engagement, such as industry bestpractice analyses, which use the assuree's information only in highly aggregated and disguised form.

The assuror may suggest ways of sharing profits with the assuree, and may also add value by suggesting new types of transactions whose cost can be lowered by assurance, but the assuror may not be able to market such products on its own. The effective veto power of the assuree over the CA output means that the concerns of managers about the proprietary nature of information may well constrain what types of CA are provided. Managers often seem to reluctant to disclose information, or even to draw attention to disclosures already made in other forms (such as in footnotes to financial statements), which again tempers what is likely to be possible in the evolution of CA.

\section{Analysis of Continuous Assurance in an ASP Setting}

To see how these issues of payment, cost, and feasibility may work in practice, consider again the case of a company outsourcing its IT systems to an ASP. As we have discussed, continuous assurance on the ASP's performance and viability is essential for the outsourcing company, given the mission-critical nature of the services provided. It is also in the ASP's interest to have such assurance available, since it enhances the value of services it provides. Such assurance, however, is not cheap or easy to provide, and the cost of providing such assurance may be prohibitive if it is not amortized over many users or other uses. Therefore, it is infeasible for the outsourcing company to choose an assurance provider to investigate an ASP. Even if the ASP agreed to be continuously investigated by different assurance providers chosen by different clients (which would be very disruptive), the cost 
of such continuous assurances would be prohibitive. Consequently, a single assurance provider will likely provide continuous assurance on an ASP to all its customers.

Who should be paying for this assurance? Two possibilities are the ASP customers and the ASP itself. If the ASP customers are directly paying the assurance provider, then it is possible to use a contract that explicitly details the obligations of the assurance provider. This type of engagement is usually thought of as enhancing the independence and objectivity of the assurance provider. However, the main difference between this continuous assurance engagement and commonly used investigations is that the ASP customers are not free to choose the assurance provider, but have to buy such assurance from the provider that has deployed the continuous assurance system at the ASP. Moreover, the more customers the ASP gets, the more revenues the assurance provider will generate. This consideration may be interpreted as implying that the assurance provider is a de facto business partner of the ASP, and this may actually impair its independence and objectivity. This potential conflict will affect the value of continuous assurance to the ASP customers, and may be detrimental to the market success of such continuous assurance engagements.

Moreover, free riding will be a major concern in this setting, with potential clients of the ASP deducing from the existence of its existing customer base that the assurance report must have been positive. The alternative of the ASP paying for continuous assurance bears significant similarities to the arrangement that is currently used for the annual audit of financial statements. The business success of the ASP has no immediate bearing on the assurance provider's revenues and, although the ASP can terminate the engagement at will, the high set-up costs of continuous assurance projects will probably inhibit opportunistic changes of continuous assurance providers.

The choice of the assurance provider becomes an interesting problem in this scenario. On the one hand, the existing external auditor of the ASP's financial statements should have an upper hand in terms of having an established relationship with the firm, deep knowledge of the ASP system, and possibly even some elements of the continuous assurance infrastructure developed to reduce the cost of the mandated audit. On the other hand, this nonstatutory engagement can be viewed as compromising the auditor's independence and possibly violating some of the recently released SEC independence rules. If these considerations become decisive, and the external auditor is not chosen as the ASP's continuous assurance provider, then the ASP will have two different assurance providers deploying their infrastructures at the ASP. This arrangement will have some similarities to the existing practice of outsourcing the company's internal audit work to a provider different from the external auditor. This example raises the point that we take up next, that as with the mandated financial statements audit, assuror independence is a critical aspect of a feasible CA environment. Without the credibility conveyed by independence, assurance has no value.

\section{ASSUROR'S INDEPENDENCE AND THE TECHNICAL ARCHITECTURE OF CONTINUOUS ASSURANCE}

Since the assuror's independence makes assurance valuable, both the assuree and the assuror should be interested in preserving independence. According to the AICPA, "assurance independence is an absence of interests that create an unacceptable risk of material bias with respect to the quality or context of information that is the subject of an assurance engagement." 8 Thus, independence implies that the assuror has no other interests - economic or psychic - in information except for its quality. We suggest that, strictly interpreted, this is a standard that is nearly impossible to achieve, even in theory. Elliott (2002) has remarked that in on-going audit engagements there must exist an auditor's independence problem (psychic interest) related to the fact that the auditor must audit the beginning balances that were already audited by the same auditor as the ending balances in the

8 http://www.aicpa.org/assurance/about/comstud/assind.htm 
previous year. Further, it is commonly assumed that the payment of audit fees by the auditee directly to the auditor creates certain independence problems. We argued above that, at least in the case of the ASP CA, if the users pay the CA fees, then this could present an independence problem as well, by creating an economic interest in the ASP's success.

Concerns about the auditor's independence were emphasized in the recent SEC independence rules, which impose serious restrictions on the auditor's involvement in the development of the auditee's financial IT systems. ${ }^{9}$ In addition, the Big 5 audit firms have felt it necessary to distance themselves from their consulting arms, in some cases even by divesting those divisions entirely.

These developments relating to independence have implications for the feasibility of CA, due to the fact that developing a comprehensive CA system requires both intimate knowledge of the firm's IT systems and cooperation of that system's developer to a much greater extent than what is necessary for a financial statement's audit. Even if an enterprise system is built using standard packaged business software, such software (e.g., SAP R/3, PeopleSoft, Oracle Applications) has extensive configuration options and is customized in significant ways to fit the needs of a particular enterprise. Although most high-end business software packages incorporate some features that facilitate auditing (the maintenance of the audit trail being the most notable one), the issue of the ability to comprehensively audit the enterprise information system is not systematically addressed by software developers.

With the design of an enterprise system either facilitating or inhibiting its auditability, the involvement of assurance providers in the design of its assurance components is unavoidable. Will such involvement jeopardize the independence of assuror? What ground rules should be put in place to preserve the assuror's independence and at the same time allow them to provide input into enterprise system design choices that facilitate its auditing? These questions can only be answered through theoretical and empirical research.

It is very likely that in the future assurors will have to be intimately involved in the design of the enterprise information systems, in particular through the development of embedded assurance modules (EAM). Since the pioneering work of Groomer and Murthy (1989), embedded audit modules have been accepted by academics as an essential technology for continuous auditing. While current versions of ERP systems neither include EAMs nor provide any real CA capability, they will undoubtedly play an essential part of the technical architecture of CA.

Such modules are much easier and cheaper to implement at the system-development stage. Overlaying such modules on an existing enterprise system is not only more difficult and costly, and but can also have unforeseen and undesirable consequences. CA systems will have to rely on embedded assurance modules to monitor the capture and processing of information in the assured system, as well as to monitor the assured system itself. The latter activity is absolutely necessary, since changes in the assured system are at least as important as its routine transactions.

The incorporation of EAMs into the company's enterprise system requires the specification of rules of interaction between them. EAMs will necessarily affect the enterprise system itself not only due to the insurmountable difficulties in debugging complex software systems, but also due to the consumption of computing and communication resources that will be associated with the presence of, or remote interaction with, EAMs. Note that without consuming some computing and communication resources, monitoring of the enterprise system is not possible. As a result, the CA system cannot be considered completely independent from the assured system, and the more comprehensive the CA system becomes, the closer this association of the assuring system with the assured system will be. This interaction problem is of a fundamental nature, and it will only become more acute over time as the methodology and technology of information processing become increasingly more sophisticated.

\footnotetext{
${ }^{9} \mathrm{http} / / /$ www.sec.gov/rules/final/33-7919.htm
} 
Although this technical dependence between the assuring and assured systems is a phenomenon that has not been traditionally raised in the discussions of auditor's independence, it may be very important in the context of CA. The assuror may well be perceived as at least partially responsible for the assuree's enterprise system, and therefore not completely independent.

\section{ISSUES FOR FURTHER RESEARCH}

The emergence of continuous reporting and assurance raises a large set of research issues as presented by Kogan et al (1999). This paper raises additional related research issues.

On the essential components of CA: How is CA related to more complex forms of management advisory services? What is the relation between mandated continuous auditing vs. the forms of ad hoc continuous assurance services that are emerging? What additional forms of non-financial and/or non-quantitative information will be the subject of CA? (Vasarhelyi and Peng 1999)

On the demand for continuous assurance: How much demand is really there by users for the large amount of raw information potentially provided by ERP-based CA systems? Are there alternative methods of providing assurance for transactions, other than CA? What is the magnitude and breakdown of demand, today, for mandated vs. nonmandated assurance services?

On paying for CA services: What types of CA reports will be paid for? Who will be the client? What is the basis for payment (time, software, etc.)? How can multiple clients pay for services?

On assuror's independence: What are the implications for assuror independence of their overlapping roles as system developers, designers of controls, and third-party assurors? Will the assuror or the assuree absorb the start-up cost and claim the ownership of the technological infrastructure of CA? What is the ideal balance of assuror and assuree interests in preserving independence?

On the technical architecture of CA: Are modern integrated ERP systems "auditable"? What is the nature and structure of embedded audit modules? What are the rules of interaction between the assured system and the EAMs?

\section{CONCLUSION}

Most of the attention and discussion of continuous assurance (CA) thus far has been paid on the technological aspects, taking for granted the economic architecture that underlies all assurance. We feel that equal weight needs to be placed on the demand for continuous assurance products and the economic infrastructure necessary to produce and pay for CA.

The essential components of assurance are (1) capturing transactional data, (2) monitoring and analyzing it, and (3) communicating the outcome of the analysis. We feel it is important to understand what continuous assurance implies for each of these steps. For example, in monitoring and analyzing transactions we identify two divergent approaches: continuous system monitoring and continuous transaction reprocessing. In considering the demand for continuous assurance, it has been argued that assurance is potentially valuable for a far wider set of transactions and stakeholders than are currently served by the mandated financial statements audit. However, we make the point that the existence of such needs does not imply that assurance is the only possible solution, or that it is economically viable even if it were.

Many issues arise concerning payment structures for continuous assurance, including what services will be provided, dealing with multiple customers, whether it is feasible to have more than one assuror in a firm at any given time, and how the free-rider phenomenon can be mitigated. We argue that the CA engagement will likely consist of a mix of specialized reports provided on demand. These reports, as well as their assurance, have economic value, and some form of cost sharing will eventually arise that will lower societal economic rents. In addition, CA will almost certainly require 
contracts that are subject to the less stringent environment of contractual law rather than the tort law that auditors face today.

Continuous assurance raises fundamental issues concerning assuror's independence and will probably re-balance the trade-offs necessary to obtain assurance objectivity. Among these issues is that systems are progressively, and increasingly, more integrated. Assuring such complex systems requires a considerably higher level of system analysis and assuror competence. In this role assurors will often suggest changes and design internal controls. This role may also present potential conflicts of independence. Our discussion suggests that a new balance of interests and rules will emerge concerning independence and objectivity issues.

\section{REFERENCES}

Q1 American Institute of Certified Public Accountants (AICPA). 1997. Report of the Special Committee on Assurance Services. Available at: http://www.aicpa.org/assurance/scas/newsvs/ reliab/index.htm.

—. 1998. CPA WebTrust. Available at: http://www.aicpa.org/webtrust/index.htm. 2000. Codification of Statements on Auditing Standards. New York, NY: AICPA

Botosan, C. A. 1997. Disclosure level and the cost of equity capital. The Accounting Review (July): 323-349.

\begin{tabular}{|c|c|}
\hline Q6 & $\begin{array}{l}\text { Canadian Institute of Chartered Accountants, and American Institute of Certified Public Accoun- } \\
\text { tants (CICA/AICPA). 1999. Continuous Auditing. Research Report. Toronto, Canada: } \\
\text { CICA. }\end{array}$ \\
\hline & $\begin{array}{l}\text { Debreceny, R., and G. Gray. 1996. E-impact of the Internet on traditional assurance services and } \\
\text { opportunities for new assurance services: Challenges and research. Available at: http:// } \\
\text { www.summa.org.uk/SUMMA/corp/papers/debreceny/audit web.htm. }\end{array}$ \\
\hline
\end{tabular}
zons 11 (4): 61-74.

- 2002. Twenty-first century assurance. AUDITING: A Journal of Practice \& Theory (March): XX-XX. [AAA will insert page numbers from this issue.]

Greenstein, M. 1998. Web site attestation-A study of licensed providers. In Collected Papers of the Seventh Annual Research Workshop on Artificial Intelligence and Emerging Technologies in Accounting, Auditing and Tax, edited by C. E. Brown, 43-56. New Orleans, LA: AAA.

Groomer, S. M., and U. S. Murthy. 1989. Continuous auditing of database applications: An embedded audit module approach. Journal of Information Systems 3 (2): 53-69.

Q6 Halper, F. B., J. Snively, and M. A. Vasarhelyi. 1992. The continuous process audit system: Knowledge engineering and representation. EDPACS 20 (4): 15-22.

Kogan, A., E. F. Sudit, and M. A. Vasarhelyi. 1999. Continuous online auditing: A program of research. Journal of Information Systems 13 (2): 87-103.

Rezaee, Z., A. Sharbatoghlie, R. Elam, and M. A. Vasarhelyi. 2002. Continuous auditing: Building automated auditing capability. AUDITING: A Journal of Practice \& Theory (March): $\mathbf{X X}-\mathbf{X X}$. [AAA will insert page numbers from this issue.]

Salterio, S. 2000. Expanding assurance services: An update from the assurance services executive committee. The Auditor's Report 23 (3). Available at: http://accounting.rutgers.edu/raw/ aaa/audit/Pubs/Audrep/00summer/item03.htm.

Srivastava, R. P., and T. J. Mock. 1999-2000. Evidential reasoning for WebTrust assurance services. Journal of Management Information Systems 10 (3): 11-32.

Vasarhelyi, M. A., and F. B. Halper. 1991. The continuous audit of online systems. AUDITING: A Journal of Practice \& Theory 10 (1): 110-125.

- $\longrightarrow$, and K. J. Ezawa. 1991. The continuous process audit system: A UNIX-based auditing tool. The EDP Auditor Journal 3: 85-91. 
— and Control Journal 5: 45-48.

Q2 and M. L. Greenstein. 2001. The electronization of business: Managing the edge. Unpublished manuscript.

Q5 - Forthcoming. Concepts in continuous assurance. In Researching Accounting as an Information Systems Discipline, edited by S. Sutton, and V. Arnold. Sarasota, FL: AAA.

Voarino, P., and M. A. Vasarhelyi. 2001. Continuous performance and control monitoring at BIPOP. Working paper, Rutgers University.

Q3 Wechler, S. 2001. Implementation of Continuous Assurance in the Real Estate Industry. CITY, STATE: Ernst \& Young.

Woodroof, J., and D. Searcy. 2001. Continuous audit implications of Internet technology: Triggering agents over the Web in the domain of debt covenant compliance. Paper presented at the 34th Hawaii International Conference on System Sciences, Hawaii, January. 